\title{
РАЗДЕЛ ХІ. МАТЕРИАЛОВЕДЕНИЕ
}

\section{Дворянкин О.А., Дворянкин А.О. \\ Технология деталей, изготовленных из полимерных композиционных материалов}

Московский университет МВД России имени В.Я. Кикотя

МАДИ

(Россия, Москва)

doi: $10.18411 / s r-10-02-2021-27$

idsp: sciencerussia-10-02-2021-27

\section{Аннотация}

В статье представлена информация о новых и более надёжных конструкционных материалов, которые превосходят по своим прочностным, упругим и другим характеристикам традиционные материалы - это полимерные композитные (композиционные) материалы. Исследована технология изготовления этих материалов.

Ключевые слова: полимерные композитные (композиционные) материалы, композиты, материаловедение, технологии

\section{Abstract}

The article presents information about some new and more reliable structural materials that are superior in their strength, elasticity and other characteristics in comparison with traditional materials. They are called polymer composite materials or (composite). The technology of manufacturing this kind of materials is investigated.

Keywords: polymer composite (composite) materials, composites, materials science, technologies

Активное развитие техники в современных реалиях предполагает применение новых и более надёжных конструкционных материалов, которые превосходят по своим прочностным, упругим и другим характеристикам традиционные.

В категорию наиболее перспективных и практичных вполне заслуженно включены полимерные материалы, представленными пластиками, а также волокнами, эластомерами, стеклопластиками, углепластиками, боропластиками, абс-пластиком и фотополимерами, включая напечатанные на 3D-принтере материалы [1].

Такие конструкционные полимерные материалы в последние годы всё чаще находят достаточно активное применение в современной машиностроительной и других сферах деятельности. Возможности полимерных материалов являются чрезвычайно широкими, что обусловлено очень большим многообразием полимеров и наполнителей, особой вариабельностью составов композитов и их модификаций.

В этом плане, развитие технологии композиционных полимерных материалов определено разными научными изысканиями и многочисленными исследованиями полимерного материаловедения, потому что проблематика взаимодействия наполнителей и составляющих является сегодня очень многогранной.

Композиты представлены материалами, состоящими из пары или более основных компонентов в виде армирующих элементов и способствующей их надёжному скреплению матрицы. Композиты обладают целым рядом свойств, заметно отличных от суммарных свойств входящих в их состав компонентов.

При этом немаловажным является тот факт, что все компоненты, входящие в состав композитов, в обязательном порядке относятся к категории хорошо совместимых, а также совсем не растворимых или другим способом не поглощаемых друг друга. 
C точки зрения более широкой смысловой нагрузки, композиционные материалы - это абсолютно любые материалы, которые имеют гетерогенную структуру, состоящую как минимум из пары фаз. Благодаря такому термину или определению вполне возможно в настоящее время отнести к категории композиционных материалов абсолютное большинство существующих металлических материалов, потому что они или целенаправленно создаются многофазными, или их принято считать однофазными, но при этом, с наличием неметаллических включений. Полимерные материалы также вполне могут быть отнесены к композитам, потому что помимо основного компонента в виде полимера, содержат и различные варианты наполнителей, красителей и т.д.

В настоящее время человечество сталкивается со всевозможными полимерными материалами, как в технической сфере, так и в повседневной жизни, поэтому наличие знаний ключевых свойств и умение грамотно ими пользоваться сегодня становится необходимым довольно широкому кругу людей.

Основной класс материалов, в полной мере удовлетворяющих жёстким, достаточно часто противоречащим друг другу требованиям, включая минимальную массу конструкций, показатели максимальной прочности, высокую жёсткость и надёжность, долговечность в сложных условиях эксплуатации, представлен именно композиционными материалами.

Современные композиты способны высокоэффективно конкурировать с такими наиболее популярными конструкционными материалами, как титан, алюминий и сталь, поэтому находят широкое применение в авиации и космонавтике, наземном транспорте и химическом машиностроении, медицине и образовании, в спорте и туризме. Композиты применяются в производстве автотранспортных средств, объектов водной и железнодорожной сферы, в самолётном и ракетном строительстве, в производстве самых разных резервуаров и высокопрочных ёмкостей, а также трубопроводных систем и систем вооружения [2].

В большинстве случаев средняя стоимость композиционных материалов является очень высокой, что обусловлено определённой сложностью ряда используемых на практике технологических процессов, а также дороговизной применяемых в производстве ключевых компонентов. Тем не менее, нужно отметить тот факт, что есть возможность экономичного производства композитных материалов благодаря снижению общего числа технологических разъёмов и количества деталей, с учётом сокращения количества сборочных операций, направленных на производство сложных конструкций.

Кроме всего прочего, особенностью является снижение в полтора-два раза общей трудоёмкости производственных операций при выпуске изделий из композиционных материалов по сравнению с аналогами из традиционного металла. Особые технические свойства и высокие эксплуатационные характеристики обусловлены тем, что в процессе разработки композиционных материалов был сформулирован принцип, которым предусматривается комплексное решение всех ключевых, наиболее важных вопросов, неразрывно связанных с проблемами выбора или проектирования.

С целью максимально быстрого и грамотного выделения современных и уже существующих ранее композиционных материалов искусственного происхождения, как правило, подчёркиваются все их ключевые характеристики и основные особенности.

Как показывает практика, самым полным принято считать определение, в соответствии с которым, к композитам относятся все материалы, обладающие целым рядом признаков, представленных особенным составом, а также формой и распределением компонентов в материале, которые «запроектированы заблаговременно». Такие материалы не встречаются в природных и естественных 
условиях, поэтому создаются человеком. Кроме всего прочего, рассматриваемый выше композитный материал представлен двумя и более компонентами, различающимися по своему химическому составу, разделёнными выраженной границами.

Свойства, присущие композитному материалу, определяются каждым компонентом, который присутствует в достаточном количестве (согласно критическому содержанию). При этом, композиту характерны свойства, которыми не обладают все по отдельности взятые компоненты, входящие в его состав. Такие материалы неоднородны с точки зрения микромасштаба, а также однородны в макромасштабе.

Самые первые из известных примеры научного подхода к ключевым вопросам по созданию искусственных композиционных материалов принято относить к временному периоду появления железобетона и стеклопластиковых материалов.

Железобетон представлен стальной арматурой и бетоном, отлично воспринимающим даже сложные сжимающие нагрузки, но достаточно плохо сопротивляющимся так называемым растягивающим напряжениям. В условиях сочетания бетона и металла, представленного стандартными стальными прутками, строго определённым образом расположенными в изделии и очень хорошо воспринимающих растягивающего типа нагрузки, удаётся получить железобетоны.

Такие материалы удачно соединяют в себе все достоинства сразу двух ключевых компонентов. Самый первый патент в отношении полимерного композиционного материала, содержащегося армированную природными волокнами синтетическую смолу, был получен более века назад. С целью систематизации композитов по разным признакам, грамотной реализации процедуры выбора для производства различных деталей, а также упорядочивания терминологии в сфере материаловедения, важно пользоваться обоснованной классификацией [3].

Рассмотрим основные виды современных полимерных материалов.

Наиболее часто используемой в настоящее время является классификация всех композиционных материалов, основанная на делении в соответствии с материаловедческим признаком.

При этом, к числу самых важных признаков классификации относится материал матрицы. Название любых поли-матричных композитных материалов представлено, как правило, парой частей, в первой из которых указывается материал наполнителя, а во второй части - применяется такое слово, как «пластик» или «волокнит». К примеру, для полимерных композитов, армированных посредством стекловолокна, характерно название стеклопластики (стекловолокниты), а при применении в этом составе металлических волокон, используется название металлопластики (металловолокниты). Кроме прочего, наличие в составе органических волокон характерно для органопластиков или органоволокнитов, присутствие борных волокон свойственно боропластикам (бороволокнитам), а углеродных волокон - для углепластиков (углеволокнитов). Асбестовые волокна входят в состав асбопластиков или асбоволокнитов.

Классификация в соответствии с геометрией армирующих элементов представлена порошками или гранулами, волокнами, пластинами.

Порошковые - дисперсно-упрочненные композитные материалы армированы порошками. Самые современные волокнистые композиты армированы непрерывными и дискретными волокнами, а пластинчатые (слоистые) композитные материалы, представлены чередующимися непрерывными и дискретными пластинами.

Классификация по структурным характеристикам и расположению компонентов предполагает деление на группы, имеющие матричную, слоистую, каркасную и комбинированную структуру.

Матричная структура свойственна для дисперсно-упрочненных и армированных композитов. Материалы со слоистой структурой - это композиции, полученные из 
набора чередующихся фольгированных слоёв или листовых материалов, имеющих разную природу и составные части. Все композиты с каркасной структурой представлены разнообразными материалами, полученными в ходе пропитывания. Комбинированную структуру, кроме всего прочего, имеют разные композитные материалы, в которых содержатся комбинации, представленные первыми тремя группами.

Матричные композитные материалы достаточно часто классифицируются в соответствии с схемой армирования или по конструкционному принципу.

В зависимости от ориентации и типа арматуры композиты представлены двумя очень крупными группами - изотропными и анизотропными.

В первом случае материалы обладают одинаковыми свойствами в разных направлениях.

Свойства анизотропных материалов определяются направлениями в исследуемом объекте.

Таким образом, композиты с матричной структурой представлены хаотичноармированными и упорядоченно-армированными материалами. В хаотичноармированных содержатся армирующие элементы, представленные дисперсными включениями, а также дискретными и непрерывными волокнами. К упорядоченноармированным композитам относятся однонаправленные материалы одноосно армированного, двухосно-армированного типа и имеющие трёхосное армирование. Не менее известна классификация композитных материалов в соответствии с методами их получения, или по технологическому принципу. Согласно данной классификации такие композиты представлены материалами, полученными посредством жидкофазных и твердофазных методов, а также при помощи осаждения - напыления, комбинированными способами [4].

Существующие и активно применяемые сегодня на практике жидкофазные методы представлены пропитыванием арматурных составляющих специальными полимерами, а также предварительно расплавленными металлами.

Кроме всего прочего, очень хорошо зарекомендовал себя вариант направленной кристаллизации сплавов. Так называемые твердофазные методы, обеспечивающие получение композитных материалов, включают в себя прокатку, экструзию, ковку, штамповку, уплотнение взрывом, диффузионную сварку, волочение. Необходимо отметить тот факт, что такие композиты, получаемые твердофазными способами, применяются в порошкообразном, листовом виде. Способ осаждения - напыления заключается в нанесении с применением растворов солей и других соединений. Основным отличием комбинированных методов является последовательное или параллельное применение сразу нескольких вариантов обработки и методов. Таким образом, детали, изготовленные из полимерных современных композиционных материалов, обладают просто уникальными характеристиками и комплексными свойствами. Самыми наиважнейшими из них являются сочетание высоких прочностных характеристик с высокой коррозионной стойкостью и низкими показателями плотности [5].

Особенностью изделий из полимерно-композитных материалов является незначительный вес и достаточно высокие показатели прочности, коррозийная стойкость и лёгкость обработки, а также долговечность и невысокая себестоимость с возможностью выполнения повторной переработки.

В настоящее время находит применение несколько способов получения деталей. В первую очередь следует обратить внимание на литьё под давлением, обеспечивающее выпуск штучных изделий, различающихся формой и размерами. Данный способ предполагает предварительную пластикацию сырьевой смеси с её подачей через сопло в специально-формующие полости для последующей выдержки в 
условиях давления. Литьё требует применения режима инжекции. Не менее распространена экструзия при выпуске профильно-погонажных товаров. Предварительно осуществляется пластикация и сжатие сырьевой массы в специальном цилиндре, с формованием методом продавливания через особую экструзивную головку. Профили с высокими требованиями к показателям точности размера предполагают обязательную калибровку при помощи вакуума или сжатого воздуха.

Помимо перечисленных выше способов, на практике активно применяются также такие методы изготовления деталей, как штранг-прессование профильнопогонажных изделий, вальцевание и каландрование листовых и плёночных изделий, вибрационное прессование и вибролитьё для деталей с минеральными дисперсными наполнителями, контактный вариант формования для производства крупногабаритных деталей и изделий малонагруженного типа.

В последнее время часто используется способ центробежного формования или центробежного литья, применяемый для изготовления деталей, имеющих гладкую поверхность, включая трубы, втулки, подшипники скольжения.

Внимание привлекают и такие перспективные способы, как вакуумная инфузия с нанесением разделительного слоя (гелькоута), автоклавное формование, намотки волокнистого наполнителя, пултрузия для получения длинномерного типа профильных изделий, прессование для изделий разнообразной формы и широкой размерной линейки, инжекция по технологии «RTM» и вариант свободного литья (заливки) при переработке полимербетонов или полимерцементов.

Работа по совершенствованию технологий деталей, изготовленных из полимерных композиционных материалов, продолжается.

$$
* * *
$$

1. Кристофер Б. 3D печать: третья индустриальная революция [Текст] / Б. Кристофер - М.: АГРАФ, 2013. $-258 \mathrm{c}$.

2. Каллистер-мл. У. Д., Ретвич Д. Дж. Материаловедение. От технологии к применению (металлы, керамика, полимеры); Научные основы и технологии - Москва, 2011. - 902 с.

3. Гросберг А. Ю., Хохлов А. Р. Полимеры и биополимеры с точки зрения физики; Интеллект Москва, 2010. - 304 с.

4. Балов А.В, Ашинина О.А. Мировой рынок биополимеров// The Chemical Journal .Март 2012 г-№3ㄷ.49-53.

5. Физико-химические методы исследования полимеров: учебное пособие. 2-е издание / В. М. Сутягин, А. А. Ляпков. - Томск: Издательство Томского политехнического университета, 2010. $140 \mathrm{c}$. 